\title{
Measuring Acculturative Stress and General Self- Rated Health of Internal Migrant Students in Indonesia: Considering Social Identity Theory
}

\author{
Nugraha Arif Karyanta ${ }^{1}$ \\ ${ }^{1}$ Department of Psychology, Universitas Sebelas Maret, Surakarta, Indonesia \\ *Corresponding author.Email:nugrahaarif@uns.staff.ac.id
}

\begin{abstract}
Ethnic identity and national identity are aspects of social identity that bring with them pros and cons in relation to acculturative stress and individual health more generally. As a multicultural country made up of various ethnic groups, Indonesia places a high importance on the concepts of ethnic identity and national identity, and how these twinned concepts affect individuals' physical and mental health. This study aims to identify the effect of national identity and ethnic identity on acculturative stress and general self-related health. Research was conducted on 251 university students who were Indonesian internal migrants, originating from various parts of Indonesia and studying at various universities in Central Java and Yogyakarta. The results of this study show that national identity is a construct that is better able to reduce the risk of acculturative stress and moreover has a positive effect on general self-rated health. Meanwhile, ethnic identity has the opposite effect, where ethnic identity is actually closely related to acculturative stress among students who are Indonesian internal migrants. We discuss the Implications, limitations and future research directions arising from this study.
\end{abstract}

Keywords: Acculturative stress, general self-rated health, internal migrant students, social identity.

\section{INTRODUCTION}

The process of acculturation as a result of cultural encounters with different ethnic groups is part of the classic definition of acculturation [1] which includes a phenomenon that occurs when a group of people from different cultures are having a continuous faceto-face encounter (continuous first hand contact) followed by certain pattern changes of original culture from one or both groups. Berry [2] further stated that although this term tends to sound neutral, since acculturation can occur in both groups, acculturation actually tends to have more of an effect one of the groups, in this case mainly the minority group. The concept of acculturation was first conceptualized as a group phenomenon, however this phenomenon has been more recognized later on at the individual level which is described by Graves [3] as psychological acculturation, referring to the internal processes and psychological changes that occur as a result of the individual acculturation process as stated by Berry [2] and Padilla and Perez [4]. This psychological acculturation can occur in six areas: language, cognitive style, personality, identity, attitude, and acculturative stress [5].

Acculturative stress can be defined as a negative consequence of the encounter of two different cultural groups, which often has a negative effect on the physiological, psychological, and social state, which necessitates adaptation to a new culture [6][7]. This resulting stress often arises from differences in social customs, norms, and values, as well as different standards in education, politics, etc., between two different cultures [8]. Behavioural changes as a consequence of the acculturation process can occur at a small level or at a more substantial level, also varying from being very easily surmountable to being a major source of cultural disruption. These changes can occur not only in a series of more manageable behavior changes (such as how to eat, talk, and dress), but also can be more problematic, causing acculturation stress that manifests itself through uncertainty, anxiety or depression. 
Like other groups of migrants, students who migrate to get a better education also experience various obstacles, including those related to adaptation to the environment, culture and new conditions they face. Various studies have shown that the adaptation process to a new place can create strong feelings of stress [9][10], and the migration process can affect both physical and mental health, e.g. causing diabetes mellitus and immune system breakdowns [11]. Native Americans who migrate within America show psychoneurotic and neurotic symptoms, as noted by Kleiner and Parker [12]

Although several studies have shown the effect of acculturative stress on mental and physical disorders experienced by migrants [11] [12], the number of studies on the effect of acculturative stress on health in general are very few. There are more studies that talk about the effect of acculturative stress on mental health, in general aspects of life [13][14] and healthquality aspect, as well as several other mental health related issues. This article talks about the effect of acculturative stress on overall health issues, especially those related to self-rated health.

\subsection{Theoretical Framework}

\subsubsection{Acculturative Stress and Health}

One of the studies that links acculturative stress with health in general is from Lone and Singh [15] The study was conducted on 219 students who came from Kashmir who were studying in Bhopal. The results of the study in general has supported the hypothesis that acculturative stress has a relation with the general self-rated health of the respondents, where the higher the cultural stress they have, the lower the participants rate their level of health. Aside from the direct relation between acculturative stress and health, several studies have tried to reveal the mechanisms between these two variables. Garcia, Winbold \& Mangold [16] (2017) tried to examine the effect of the cortisol awakening response (CAR) mediator variable between these two variables. Results from the study showed stress-induced changes in CAR have mediated the relationship between exposure to acculturation stressors and selfrated health.

Literature that discusses the relationship between the effect of the acculturation process, including acculturative stress, and the individual's health are still very limited, especially the ones that include cultural variables. Cultural variables have become an important aspect in this process because the acculturation process will certainly involve cultural factors. Fox, Thayer and Wadhwa [17] conducted a review on the relation of acculturation and health by considering the social context as a moderating variable. The results of the review conducted show that various social contexts need to be investigated more deeply to see the link between acculturation and health. This result shows that research on the processes and mechanisms of acculturation that give effect on health is still rarely found and has not yet been able to answer the existing problems.

In considering health, this study uses the term "General self-rated health" which is more commonly known as self-rated health (SRH). Self-rated health (SRH), also known as "self-rated health status", "general self-rated health" or "self-reported health", is a means of measuring the level of self-perceived or subjective morbidity [18]. Furthermore, SRH is a concept commonly used in epidemiological and public health journals. Some people might consider this kind of subjective measurement to be insufficient, but some experts think that at the societal level this measurement model is sufficient enough. One of the problems of using self-rated health as a measure is that respondents' answers may not only reflect the objective conditions of their health level, but can also be influenced by the expectations and norms that individuals, groups and communities have for that level of health. Therefore, as van Ginneken and Groenebald [18] have stated, measurement using this model is acceptable as long as the interpretation of the data obtained also considers these cultural and normative factors.

\subsubsection{Social Identity and Health}

The acculturation process always involves a change in ethnic identity, which is defined as the sense of belonging felt by a person towards their ethnicity [19]. Berry's [20] acculturation strategy framework, for example, uses the "preservation of culture and identity" axis, which reflects the strengthening or rejection of minority cultures. However, studies on the transformation of ethnic identity in relation to acculturative stress still give less conclusive results. Nedale, Rooney and Smith [21] for example, hypothesize that the more strongly 
immigrants identify with their own ethnicity, the more likely it is for the host community to see them as different. Therefore, if immigrants try hard to affiliate themselves to their original culture in a society that supports assimilation, this will lead to an increased experience of discrimination against the immigrant, and therefore an increase of stress level. On the other hand, they may choose to loosen the bonds of their ethnic identity; various other studies have shown a positive relationship between ethnic identity and mental health. For example, research by Tzuriel and Klein [22] on Israeli teenagers shows a very strong relation between ethnic identity and ego identity, especially research with subjects from developing countries who show a higher need for ethnic identity in minority communities. Another study from Nesdale et al. showed a relation between ethnic identity and self-esteem [21].

Various articles have highlighted the pros and cons of the concept of ethnic identity on various issues. For example, for the pro section, ethnic identity has been shown to be a variable with a moderating effect on the relationship between depression and suicidal ideation [23]. On various occasions, there have been various studies showing how ethnic identity is a factor in a person's mental health. But among these various things, research from Seo and Moon [24] shows that strongly felt ethnic identity also tends to prevent a person from participating more broadly in society. This might have relation to the hypothesis expressed by Nesdale [21] that adult immigrants who have a strong ethnic identity associated with their culture of origin may be perceived as different from the host culture and receive discriminatory treatment. However, adult immigrants who choose to assimilate also face an equally complicated situation, where they may experience less discrimination from the wider community, but will face higher pressure from their own group, which also creates high levels of psychological distress.

The concept of national identity is often contrasted with the concept of ethnic identity in discussions about the acculturation process, where the attarction of national identity will most likely lead to a process of assimilation [25], while on the other hand ethnic identity has the potential to prevent someone from participating widely in society [24]. Several studies have shown that national identity has an influence on immigrant self adjustment [26]. This is perhaps related to the fact that the sense of social distance between various ethnic groups tends to loosen up when there is a stronger priority on national identity, so that there is more harmonious contact between groups [27].

\subsubsection{Social Identity and Acculturative Stress}

In various articles, ethnic identity and acculturative stress are treated as social constructs that are of equal weight and are not within a framework of mutual influence. Constructs of ethnic identity and acculturative stress were most associated with depression in various communities, especially as moderating variables associated with depression. Several articles, such as those from Musso, Inguglia and Lo Cocco [28] and Kim, Hoge and Salvisberg [29] have traced the influence of ethnic identity on acculturative stress experienced by a person.

\subsection{Conceptual Framework}

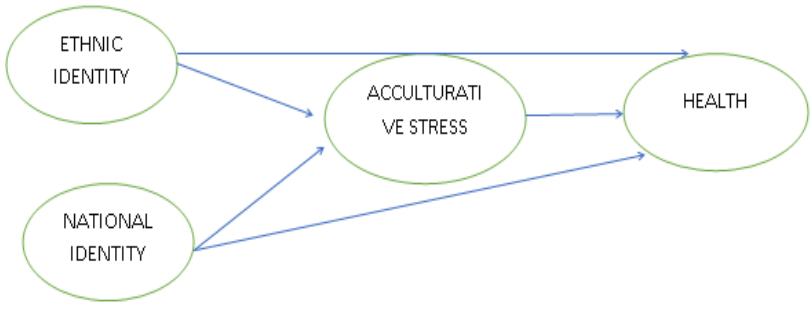

\subsection{Hypothesis}

(H1) There is a negative relationship between acculturative stress and health

(H2) There is a negative relationship between ethnic identity and acculturative stress

(H3) There is a negative relationship between national identity and acculturative stress

(H4) There is a positive relationship between ethnic identity and health

(H5) There is a positive relationship between national identity and health 


\section{METHOD}

\subsection{Participants}

The participants in this study were 251 university students, internal migrants from various ethnic groups in Indonesia who were studying at various universities in Central Java and Yogyakarta. The selection of participants was carried out using purposive sampling.

\begin{tabular}{|l|l|l|l|}
\hline & & Total & Percentage \\
\hline Gender & Men & 83 & $33 \%$ \\
\hline & Women & 168 & $67 \%$ \\
\hline Age & $18-21$ & 226 & $90 \%$ \\
\hline $\begin{array}{l}\text { Duration } \\
\text { living in } \\
\text { Java }\end{array}$ & $>21$ & 25 & $10 \%$ \\
\hline & $1-2$ year & 30 & $12 \%$ \\
\hline & $2-4$ year & 105 & $42 \%$ \\
\hline & $>4$ year & 64 & $25 \%$ \\
\hline
\end{tabular}

\subsection{Procedure}

The online questionnaire was distributed to groups of internal migrant students in Central Java and the Special Region of Yogyakarta. Completing the questionnaire took 20-30 minutes.

\subsection{Measurement}

\subsubsection{General Self-Rated Health}

The use of single-item measurement still leads to differences of opinion among experts. However, in general, experts in the field of psychometrics hold the same point of view that measurement with the single item can be justified, by factoring in the possible drawbacks of the method [30]. In connection with the measurement of individuals' state of overall health, Cunny and Perri [31] (1991) found that a single item from the Medical Outcome Study Survey can serve as a substitute for measurements using the full 20 items. The single item was the question "In general, would you say your health was Excellent, Very Good,
Good, Fair, or Poor?", and had a very high correlation $(\mathrm{r}=.86)$ with the overall score. In this study, the wording used for the item was: If you look at life in general these days, how healthy or unhealthy are you? Participants were asked to respond to these questions by choosing one of the five choices Very Good, Good, Fair, Poor, or Very Poor.

\subsubsection{Acculturative Stress}

In this study, acculturative stress was measured using an adaptation scale of the Acculturative Stress Scale for International Students or often referred to as ASSIS [32] with seven principal factors, namely (1) homesickness; (2) culture shock; (3) perceived discrimination; (4) perceived hate; (5) fear; (6) guilt; and (7) miscellaneous. The higher the ASSIS score, the higher the level of acculturative stress experienced by the respondents, and vice versa.

Several studies using ASSIS show evidence that this measuring tool is reliable enough to use. Yun [33] revealed a cronbach alpha value of .91 which indicates high internal consistency. Meanwhile, Guttman's split-half reliability value is .840 with .733 as the correlation between forms. These indicate high reliability. Akhtar [34] states that the ASSIS internal consistency score moves from .87 to .95 using cronbach alpha. Sandhu and Asrabadi [35] reported a Cronbach alpha value of .94 with Guttman's split-half reliability of .96 . The validity of the construct is supported by a positive relationship with depression in international students [36].

\subsubsection{Ethnic Identity}

Ethnic identity refers to the quality of an individual's affiliation with his ethnic group [37]. Conceptualized as a multidimensional construct, the development of ethnic identity includes a process of exploring the meaning of ethnic identity and the commitment that individuals have to that identity. When we refer to ethnic identity in this study we use Multigroup Ethnic Identity Measurement (MEIM) $\mathrm{R}$, to measure both aspects of ethnic identity (exploration and commitment) [38].

\subsubsection{National Identity}

National identity is measured using the general national pride (GNatPr), which is a modification of the single item question "how proud are you to be/to be seen as a member of [country / nationality]" [39]. 
Participants were asked to respond by choosing one of five alternative answer choices ranging from very proud to very not proud. Previous studies have used these items as indicators for national identity: national belonging, national pride, patriotism, and nationalism

\section{RESULT}

This research wanted to test the fitness of the structural model built, and then after affirming that the model is fit enough, the hypothesis above will be

\begin{tabular}{|c|c|c|c|c|}
\hline & $\begin{array}{c}\text { Type of } \\
\text { Test }\end{array}$ & $\begin{array}{c}\text { Require } \\
\text { ment }\end{array}$ & Output & $\begin{array}{l}\text { Fulfil } \\
\text { lment }\end{array}$ \\
\hline \multirow{4}{*}{ Absolute } & $\mathrm{X} 2$ & $>\alpha 0.05$ & 0.0000 & $\mathrm{NO}$ \\
\hline & RMSEA & $<0.08$ & 0.076 & YES \\
\hline & RMR & $<0.05$ & 0.33 & $\mathrm{NO}$ \\
\hline & $\begin{array}{l}\text { GFI/AG } \\
\text { FI }\end{array}$ & Min 0.9 & $0.94 / 0.89$ & YES \\
\hline \multirow{5}{*}{$\begin{array}{l}\text { Incremen } \\
\text { tal }\end{array}$} & NNFI & Min 0.9 & 0.96 & YES \\
\hline & NFI & x 0.9 & 0.95 & YES \\
\hline & RFI & x 0.9 & 0.93 & YES \\
\hline & IFI & x 0.9 & 0.97 & YES \\
\hline & CFI & x 0.9 & 0.97 & YES \\
\hline \multirow{5}{*}{$\begin{array}{l}\text { Parsimon } \\
\text { y- } \\
\text { adjusted }\end{array}$} & PNFI & $0.6-0.9$ & 0.67 & YES \\
\hline & PGFI & $0.6-0.9$ & 0.55 & $\mathrm{NO}$ \\
\hline & AIC & $\begin{array}{l}\text { Est. < sat } \\
\text { model }\end{array}$ & & NO \\
\hline & CAIC & $\begin{array}{l}\text { Est. < sat } \\
\text { model }\end{array}$ & & NO \\
\hline & & & & \\
\hline
\end{tabular}

tested, as summarized in Table 1 .

Table 1. Goodness of Fit

\subsection{Path Coefficient}

The following is the model ( $\mathrm{T}$ value) obtained from the output of LISREL, as shown in Figure 1 below:

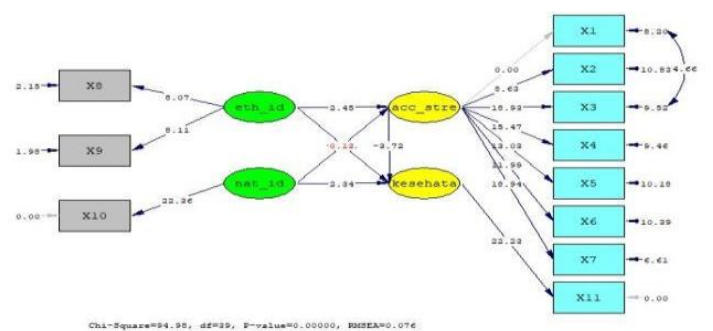

Figure 1. Path Analysis

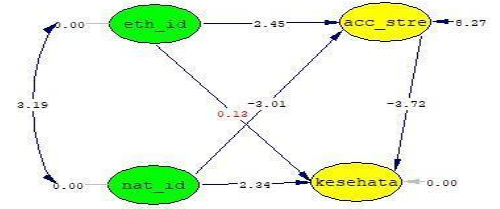

\subsection{Discussion}

The absolute parameters of the fit model above indicate that the two parameters do not meet the specified criteria (X2 and RMR), while the RMSEA shows the characteristics of fit indices. It is just a little under 0.08. Citing Diamantopoulos, Hopper et al. (2008) RMSEA is referred to as "one of the most informative indices". The two parameters of fit indices that do not meet the specified margin are closely tied to the number of samples used in the analysis. The limited sample size, which is only 251 data points, seems to be the determinant of the poor fit for the model as regard these three parameters.

Meanwhile, parameters that are freer with regards the number of samples have fit indices that meet the established standards. In incrimental fit indices, all parameters, namely NNFI, NFI, RFI, IFI, and CFI show fulfillment in these requirements, although not all are in a satisfactory range, but at least they are still acceptable. Meanwhile for parsimony-adjusted parameters, PGFI, AIC and CAIC show that the model is not acceptable. However, as regards the PNFI score, the model is still acceptable. These various parameters show that the model is acceptable, thus it can be said that the model can represent the data well. The implication is that the researcher can make a valid inference.

The calculated value in the structural equation shows that there is a negative relationship between acculturative stress and health, so that hypothesis 1 (H1) is accepted. The t score of -3.72 which is greater than the t-table, namely 1.98 , indicates that the difference is significant. Meanwhile, hypothesis 2 $(\mathrm{H} 2)$, that there is a negative relationship between ethnic identity and acculturative stress, is rejected, as it shows that ethnic identity has a positive relationship with acculturative stress. The structural 
model also shows a negative relationship between national identity and acculturative stress, so that hypothesis 3 (H3) can be accepted. Hypothesis 4 (H4), that there would be a positive relationship between ethnic identity and health, is rejected because although the relationship between the two variables is positive, it is very small and insignificant $(\mathrm{t}=0.13<\mathrm{t}$ table 1.98). Furthermore, hypothesis 5 (H5), which suggested a positive relationship between national identity and health in general, can be accepted.

The various results shown here tend to frame national identity as a construct that is more likely able to reduce the risk of acculturative stress on internal migrant students in Indonesia. The results regarding ethnic identity tend to demonstrate that a stronger ethnic identity can affect acculturative stress and health in general. This may align to research from Seo and Moon [24] showing that a strong ethnic identity also tends to prevent a person from participating more broadly in society.

\subsection{Conclusion}

This study concludes that there is a negative correlation between acculturative stress and health. The similar negative correlation is shown between national identity and acculturative stress. However, positive relationships are shown between ethnic identity and acculturative stress, also between national identity and health.

\section{AUTHOR'S CONTRIBUTIONS}

The author confirms sole responsibility for the following: study conception and design, data collection, analysis and interpretation of results, and manuscript preparation.

\section{ACKNOWLEDGMENTS}

The author thanked to the participants who took part in this study.

\section{REFERENCES}

[1] R. Redfield, R. Linton, M. J. Herskovits. Memorandum for the study of acculturation. Am. Anthropol. 38(1) (1936) 149 - 152.
[2] J. W. Berry, Immigration, Acculturation and Adaptation, Applied Psychology: Int. Rev. 46(1) (1997) 5-68.

[3] T. Graves, Psychological acculturation in a triethnic community. Southwest J Anthropol 23 (1967) 337-350.

[4] A. M. Padilla, W. Perez. Acculturation, social identity, and social cognition: a new perspective. Hisp. J. Behav. Sci. 25(1) (2003) 35-55

[5] J. W. Berry, Acculturation as varieties of adaptation. In A.M. Padilla (Ed.), Acculturation: Theory, models and some new findings, Boulder, CO: Westview Press, 1980.

[6] J. W. Berry, U. Kim, T. Minde, D. Mok, Comparative studies of acculturative stress, Int. Migr. Rev., 21(3) (1987), Special Issue: Migration and Health, 491-511.

[7] S. Poyrazli, P. R. Kavanaugh, A. Baker, N. AlTimimi. Social support and demographic correlates of acculturative stress in international students. J. Coll. Couns. 7 (2004) 73-82.

[8] C. J. Yeh, P. W. Ma, A. Madan, C. D. Hunter, S. Jung, A. Kim, K. Akitaya, K. Sasaki, The cultural negotiation of Korean immigrant youth. J Couns Dev. 83 (2005) 172-181.

[9] T. H. Holmes, R. H. Rahe. The Social Readjusment Rating Scale. J. Psychosom. Res, 11 (1967) 213-218.

[10] A. Vingerhoets, The Homesickness Concept: Questions and Doubts. Dalam van Tilburg, A. Vingerhoets. Psychological Aspects of Geographical Moves: Homesickness and Acculturation Stress, 2005, Amsterdam: Amsterdam Academic Archive.

[11] M. A. L. Van Tilburg, A. J. J. M. Vingerhoets, G. L, Van Heck. Homesickness: A review of the literature, 1996, Psychol. Med. 26 (1996) 899-912.

[12] S. Fisher. Geographical Moves and Psychological Adjustment. Dalam G. L., van Tilburg, A. A. J. M., Vingerhoets. 
Psychological Aspects of Geographical Moves: Homesickness and Acculturation Stress. Amsterdam: Amsterdam Academic Archive. 2005

[13] S. R. Sirin, P. Ryce, T. Gupta, L. R. Sirin, The Role of Acculturative Stress on Mental Health Symptoms for Immigrant Adolescents: A Longitudinal Investigation. Dev. Psychol. 49(4) (2013) 736 -748.

[14] L. J. Albeg, S. M. Castro-Olivio. The Relationship between Mental Health, Acculturative Stress, and Academic Performance in a Latino Middle School Sample. Contemp. Educ. Psychol. 18, (2014) 178-186.

[15] M. A. Lone, T. Singh, Relationship of Acculturative Stress and Health among Kashmiri Students in Bhopal, Indian Contemp. Educ. Psychol. 37(2) (2011) 269276.

[16] A. F. Garcia K. Wilborn, D. L. Mangold, The Cortisol Awakening Response Mediates the Relationship Between Acculturative Stress and Self-Reported Health in Mexican Americans, Ann Behav Med. 51(6) (2017) 787-798. doi:10.1007/s12160-017-9901-5

[17] M. Fox, Z. Thayer, P. D. Wadhwa, Acculturation and health: the moderating role of socio-cultural context, Am. Anthropol. 119(3) (2017) 405-421. doi:10.1111/aman.12867.

[18] J. K. Van Ginneken, G. Groenewold, A Singlevs. Multi-Item Self-Rated Health Status Measure: A 21-Country Study, Open Publ Health J. 5 (2012) 1 - 9.

[19] J. S. Phinney, Ethnic identity in adolescents and adults: Review of research. Psy Bul. 108 (1990) 499-514.

[20] J. W. Berry, D. L. Sam, Theoretical perspectives, In D. L. Sam, J. W. Berry, The Cambridge Handbook of acculturation psychology, 2016, Cambridge University Press.
[21] D. Nesdale, R. Rooney, L. Smith, Migrant ethnic identity and psychological distress, J. CrossCult. Psychol. 28 (1997) 569-588.

[22] D. Tzuriel, M. M. Klein, Ego Identity: Effects of ethnocentrism, ethnic identification, and cognitive complexity in Israeli Oriental and Western ethnic groups. Psychol. Rep. 40(3) (1977) 1099-1110. DOI: 10.2466/pr0.1977.40.3c.1099.

[23] R. L. Walker, E. M. Obasi, R. R. Wingate, T. E. Joiner, An Empirical Investigation of Acculturative Stress and Ethnic Identity as Moderators for Depression and Suicidal Ideation, College Students. Cult. Divers. Ethn. Minor. Psychol. 14(1) (2008) 75 - 82.

[24] M. Seo, S-G. Moon, Ethnic identity, acculturative stress, news uses, and two domains of civic engagement: a case of Korean Immigrants in the United States. Mass Commun Soc. 16 (2013) 245-267.

[25] P. Grajzl, J. Eastwood, V. Diimitrova-Grajzl, Should immigrants culturally assimilate or preserve their own culture? Host-society natives' beliefs and the longevity of national identity. Soc. Sci. Res. 75 (2018) 96-116.

[26] E. Sher-Censor, M. Benish-Weisman, L. Gal, S. Karni, The Association between National Identity and Adjustment: What Can We Learn from Autobiographical Narratives?. Int J Intercult Relat. 67 (2018) 12 -24.

[27] R. Bilali, Y. Iqbal, A. BetulCelik, The role of national identity, religious identity, and intergroup contact on social distance across multiple social divides in Turkey. Int. J. Intercult. Relat. 65 (2018) 73-85.

[28] P. Musso, C. Inguglia, A. Lo Cocco, Relationships Between Ethnic Identity, Ethnic Attitudes, and Acculturative Stress in Tunisian Individuals in Early and Middle Adolescence, J. Early Adolesc. 37 (2016)

[29] E. Kim, I. Hogge, C. Salvisberg, Effects of selfesteem and ethnic identity: Acculturative stress and psychological well-being among Mexican immigrants. Hisp. J. Behav. Sci., 36(2) (2014) 144-163. DOI: $10.1177 / 0739986314527733$ 
[30] G. G. Fisher, R. A. Matthews, A. M. Gibbons, Developing and investigating the use of single-item measures in organizational research. J. Occup. Health Psychol. 21(1) (2016) 3-23. DOI: 10.1037/a0039139.

[31] K. A. Cunny, M. Perri, Single-Item vs MultipleItem Measures of Health-Related Quality of Life. Psychol. Rep. 69(1) (1991) 127-130. DOI: 10.2466/PRO.69.5.127-130.

[32] D. S. Sandhu, B. R. Asrabadi, Development of an acculturative stress scale for international students: Primary findings, Psychol. Rep. 75 (1994) 435-448

[33] S. R. Yun, The relationship between acculturative stress level and perceived social support among korean international students, 1998, Tesis, California: California State University.

[34] A. Akhtar, A. Rahman, M. Husain, N. Husain, Multidimensional scale of perceived social support: Psychometric properties in a South Asian population. J Obstet Gynaecol Res.36(4) (2010) 845-51. DOI: 10.1111/j.1447-0756.2010.01204.x.

[35] D. S. Sandhu, B. R. Asrabadi, An acculturative stress scale for international students: A practical approach to stress management. In C.P. Zalaquett \& R.J. Wood (Eds.), Evaluating stress: A book of resources. Vol. 2. 1998. pp. 1-33. Lanham, MD: The Scarecrow Press.

[36] M. G. Constantine, S. Okazaki, S. O. Utsey, Self-Concealment, Social Self-Efficacy, Acculturative Stress, and Depression in African, Asian, and Latin American International College Students. Am. J. Orthopsychiatry. 74(3) (2004) 230-241.

[37] J.S. Phinney, A.D. Ong. Conceptualization and Measurement of Ethnic Identity: Current Status and Future Directions. J. Couns. Psychol. 54(3) (2007) 271-281. DOI: 10.1037/0022-0167.54.3.271.

[38] S. D. Brown, K. A. Unger Hu, A. A. Mevi, M. M. Hedderson, J. Shan, C. P. Quesenberry, A. Ferrara, The multigroup ethnic identity measure-revised: measurement invariance across racial and ethnic groups. J. Couns. Psychol. 61(1) (2014) 154-161. DOI:10.1037/a0034749.

[39] K. Meitinger, What does the general national pride item measure? Insights from web probing. Int J Comp Sociol. 59(5-6) (2018) DOI:10.1177/0020715218805793. 